\title{
Extratropical Response to the MJO: Nonlinearity and Sensitivity to the Initial State
}

\author{
HAi LiN AND GILBERT BRUNET \\ Meteorological Research Division, Environment and Climate Change Canada, Dorval, Quebec, Canada
}

(Manuscript received 20 June 2017, in final form 2 October 2017)

\begin{abstract}
Previous studies have shown that the Madden-Julian oscillation (MJO) has a global impact that may provide an important source of skill for subseasonal predictions. The extratropical response was found to be the strongest when the tropical diabatic heating has a dipole structure with convection anomaly centers of opposite sign in the eastern Indian Ocean and the western Pacific. A positive (negative) MJO dipole heating refers to that with heating (cooling) in the eastern Indian Ocean and cooling (heating) in the western Pacific. In this study, two aspects of the extratropical response to the MJO are examined: 1) nonlinearity, which answers the question of whether the response to a positive MJO dipole heating is the mirror image of that to a negative $\mathrm{MJO}$, and 2) sensitivity to the initial state, which explores the dependence of the extratropical response on the initial condition of the westerly jet.

Ensemble integrations using a primitive-equation global atmospheric circulation model are performed with anomalous tropical thermal forcings that resemble a positive MJO (+MJO) and a negative MJO $(-\mathrm{MJO})$. The response in the first week is largely linear. After that, significant asymmetry is found between the response in the positive MJO and the negative MJO. The 500-hPa negative geopotential height response in the North Pacific of the $-\mathrm{MJO}$ run is located about $30^{\circ}$ east of the positive height response of the $+\mathrm{MJO}$ run. There is also an eastward shift of the extratropical wave train in the Pacific-North American region. This simulated nonlinearity is in agreement with the observations. The two leading response patterns among the ensemble members are identified by an empirical orthogonal function (EOF) analysis. EOF1 represents an eastward shift of the wave train, which is positively correlated with strengthening of the East Asian subtropical upper-troposphere westerly jet in the initial condition. On the other hand, EOF2 represents an amplification of the response, which is associated with a southward shift of the westerly jet in the initial state.
\end{abstract}

\section{Introduction}

The Madden-Julian oscillation (MJO) is the dominant mode of variability in the tropics on a subseasonal time scale. The large-scale tropical diabatic heating associated with the MJO induces Rossby waves that propagate poleward and eastward, thus influencing the extratropical atmospheric circulation and weather. For example, the MJO was found to influence boreal winter Northern Hemisphere teleconnections (e.g., Mori and Watanabe 2008; Cassou 2008; L'Heureux and Higgins 2008; Lin et al. 2009). The MJO was found to have a substantial systematic and spatially coherent effect on subseasonal variability in wintertime surface air temperature in the Arctic region (Vecchi and Bond 2004; Yoo et al. 2012a,b) and North America (Lin and Brunet 2009; Zhou et al. 2012; Baxter et al. 2014). Outside the tropics, through extratropical waves and teleconnections, the

Corresponding author: Hai Lin, hai.lin@canada.ca
MJO influence on precipitation have been detected as well (e.g., Higgins et al. 2000; Mo and Higgins 1998; Bond and Vecchi 2003; Lin et al. 2010; Becker et al. 2011). Through such global impact, the MJO provides an important source of skill for subseasonal weather predictions (e.g., Waliser et al. 2003).

Extratropical response to tropical MJO forcing can be largely explained by extratropical Rossby wave propagation (e.g., Hoskins and Karoly 1981; Branstator 1985; Karoly 1983; Hoskins and Ambrizzi 1993), as demonstrated in numerical simulation experiments using idealized tropical MJO forcing (e.g., Matthews et al. 2004; Lin et al. 2010; Seo and Son 2012; Seo et al. 2016; Lukens et al. 2017). The extratropical response pattern as a response to tropical forcing can be established in about 2 weeks, as discussed in Jin and Hoskins (1995). Indeed, several observational studies have revealed significant lagged associations of the extratropical circulation anomaly with respect to the MJO. For example, as discussed in Lin et al. (2009), about 10-15 days after the 
occurrence of MJO phase 3, according to the definition of Wheeler and Hendon (2004), which corresponds to dipole of tropical convection anomaly (enhanced convection in the tropical Indian Ocean and reduced convection in the tropical western Pacific), a positive phase of the North Atlantic Oscillation (NAO) tends to occur. The NAO is a dominant circulation pattern in the Northern Hemisphere, influencing weather over North America and Europe (e.g., Hurrell et al. 2003). The reverse phase of the dipole (i.e., MJO phase 7) would then likely be followed by a negative NAO. Such a dipole structure of the tropical convection anomaly is the most effective in exciting extratropical circulation anomalies (e.g., Lin et al. 2010).

Atmospheric response to tropical dipole MJO forcing can be reasonably well simulated by a linear model (e.g., Lin et al. 2010; Seo and Son 2012), indicating that linear processes are dominant. However, it is interesting to know whether the atmospheric response to MJO phases 6 and 7 is the mirror image of that to MJO phases 2 and 3 -that is, an MJO forcing of the same dipole pattern but with an opposite sign. To what extent is the response nonlinear? From Matthews et al. (2004), evidence of nonlinearity was seen where the midlatitude response is weaker when there is anomalous tropical cooling to the east of anomalous heating than when a heating anomaly is located to the east of anomalous cooling. Their explanation is that the Pacific jet is stronger and extended when heating is to the east of cooling, and the jet would then act as a more efficient waveguide trapping barotropic Rossby waves and leading to larger wave amplitude downstream over North America. However, this is in contrast with the two-level model result of Bladé and Hartmann (1995), who found that the midlatitude response is inhibited when heating is located to the east of cooling, which they attributed to the effect of anomalous easterly flow on the equator. The nature of nonlinearity and its dynamics associated with response to MJO dipole forcing are still unclear.

Extratropical response to the MJO differs from case to case. It can be caused by the difference in MJO forcing itself related to the vertical structure and propagating speed. It can also be related to the extratropical basic state in which the extratropical Rossby wave propagates. On a subseasonal time scale, the extratropical flow in which the Rossby wave propagates changes during the period when the response develops that further influences the response. Goss and Feldstein (2015) investigated the impact of initial flow on the extratropical response over the Pacific-North American (PNA) region to the MJO phases 1 and 5. Here we look at the sensitivity of the response to the initial atmospheric state when the MJO forcing is likely the most effective. In previous studies, statistical models were found to be able to produce useful subseasonal predictions for North American surface air temperature using the tropical MJO as a predictor (e.g., Yao et al. 2011; Rodney et al. 2013). It is possible that by combining the information of the tropical MJO and that of the initial atmospheric state, one can produce a better extratropical subseasonal prediction than using the MJO alone.

In the present study, we use a simple general circulation model (SGCM) to investigate the atmospheric response to a tropical forcing that is similar to the dipole structure of the MJO diabatic heating. The nonlinear model is integrated with a time-independent climatological forcing, which is to maintain the mean flow and transients, plus the MJO anomalous heating. This allows the full interactions between the response and the transients as well as with the mean flow from the beginning of the integrations. Large ensembles are produced from different initial conditions. Daily ensemble averages yield the signal coming from the heating/cooling source. We examine the difference between the atmospheric response to a tropical positive MJO ( $+\mathrm{MJO}$ ) heating and that to a negative $\mathrm{MJO}(-\mathrm{MJO})$ forcing and how this difference evolves with time.

Section 2 describes the data, model, and experimental design. In section 3 , by comparing the extratropical atmospheric responses to dipole MJO forcing structures with opposite signs, nonlinearity in atmospheric response is analyzed. Comparison is also made with the observations. The dependence of the response on the initial atmospheric state is discussed in section 4 . In section 5, a discussion is made on the explanation of the nonlinearity and its association with the dependence on the subtropical North Pacific westerly jet. A summary and conclusions are given in section 6 .

\section{Data, model, and experimental design}

The daily average data of the National Centers for Environmental Prediction-National Center for Atmospheric Research (NCEP-NCAR) global reanalysis (Kalnay et al. 1996) are used to represent the observed atmospheric circulation fields. Variables used here include geopotential height on $500 \mathrm{hPa}$ and zonal wind on $200 \mathrm{hPa}$. As a proxy for tropical convection, the daily averaged OLR data from the National Oceanic and Atmospheric Administration (NOAA) polar-orbiting series of satellites (Liebmann and Smith 1996) are used. These data are provided by NOAA/OAR/ESRL PSD, Boulder, Colorado, on their website at https://www.cdc.noaa.gov/.

The horizontal resolution for the NCEP-NCAR reanalysis and the OLR is $2.5^{\circ} \times 2.5^{\circ}$. The daily values are averaged for five consecutive days to construct pentad data. The analysis is conducted for 37 extended winters 


\section{a) OLR EOF $1 \quad 11 \%$}

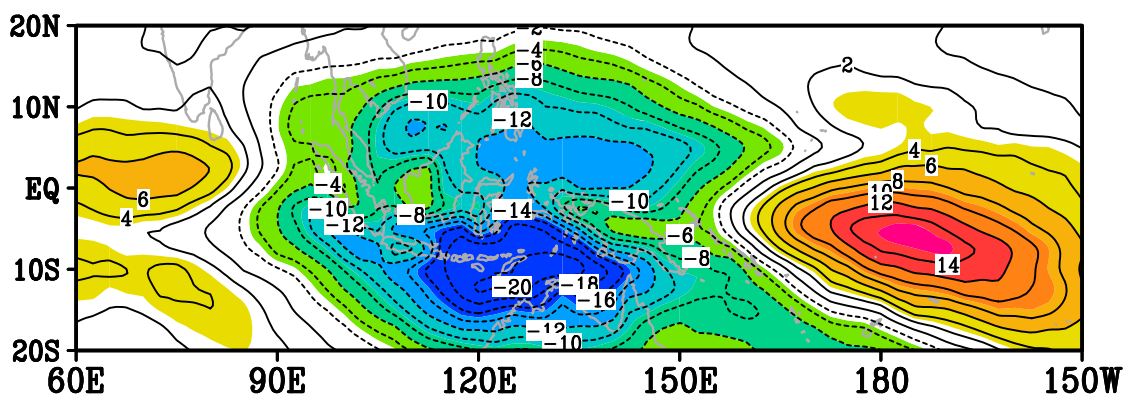

b) OLR EOF2 $10 \%$

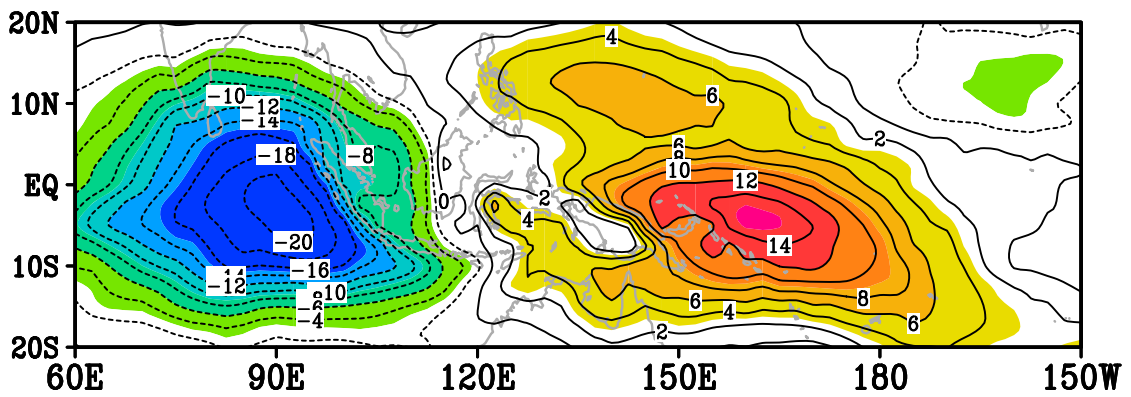

FIG. 1. (a) EOF1 and (b) EOF2 of OLR represented as regressions of pentad OLR onto the respective PC. The magnitude corresponds to one standard deviation of the PC. The contour interval is $2 \mathrm{~W} \mathrm{~m}^{-2}$. This figure is as in Fig. 2 of Lin et al. (2010), except calculated with a longer period of data.

from $1979 / 80$ to $2015 / 16$, where the extended winter is defined to be the 36 pentads starting from the pentad of 2-6 November and ending at the pentad of 26-30 April. Following Lin et al. (2009), the seasonal cycle is first removed, which is the annual mean and first two harmonics of the 37-yr pentad climatology. Then the time average of each extended winter is subtracted to remove the interannual variability. The resulting anomalies are mainly on the intraseasonal time scale.

The model used in this study is a primitive-equation dry atmospheric model as described in detail in Hall (2000) and Lin et al. (2010). In brief, it is a spectral model with a global domain. The resolution used in this study is triangular 31 , with 10 equally spaced sigma levels. Besides a scale-selective dissipation that takes the form of $\nabla^{6}$ with a time scale of $12 \mathrm{~h}$ at the smallest scale, the model also has a level-dependent linear damping that has shorter time scales for the lower levels. The model uses a time-averaged forcing calculated empirically from observed daily data. The forcing is obtained as a residual term for each time tendency equation by computing the dynamical terms of the model, together with the dissipation, with daily global analysis and averaging in time. This forcing thus maintains the observed climatology. As demonstrated in Hall (2000), this model reproduces remarkably well the stationary planetary waves and the broad climatological characteristics of the transients. This model was used to study the atmospheric response to anomalous forcings in the tropics (Lin and Derome 2004; Lin et al. 2010) and in the extratropical regions (Hall et al. 2001).

Following Lin et al. (2010), the MJO thermal forcing pattern is defined according to an empirical orthogonal function (EOF) analysis of tropical pentad-averaged OLR for the 37 extended winters from 1979/80 to 2015/16. The leading two EOFs, shown in Fig. 1, are used to define the MJO. These first two leading EOFs represent the eastward-propagating MJO. EOF1 shows an enhanced convection near the Maritime Continent region. EOF2 is characterized by a dipole structure of convection anomalies, with enhanced convection in the eastern Indian Ocean and reduced convective activity in the western Pacific, which is similar to MJO phases 2 and 3 defined in Wheeler and Hendon (2004). As demonstrated in Lin et al. (2010), such a dipole diabatic heating anomaly is the most effective in exciting Rossby wave response in the extratropical Northern Hemisphere in boreal winter. Here we define an idealized $+\mathrm{MJO}(-\mathrm{MJO})$ 

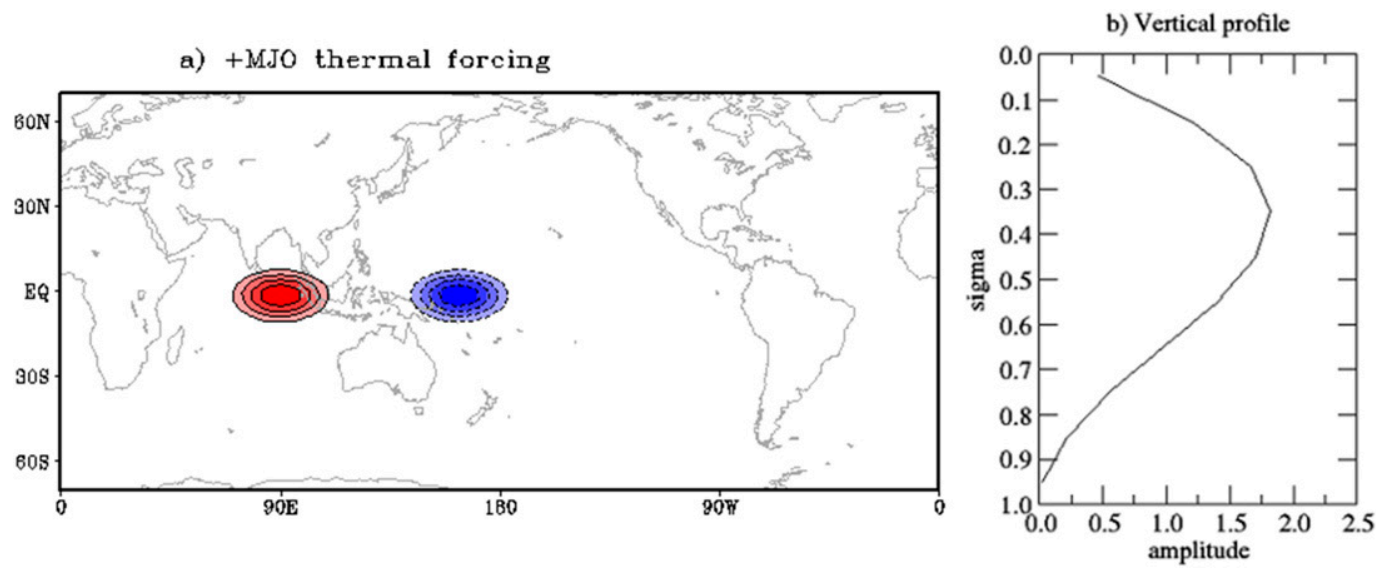

FIG. 2. (a) Vertically averaged anomalous heating rate for $+\mathrm{MJO}$ forcing. The contour interval is $0.5 \mathrm{~K} \mathrm{day}^{-1}$. The zero contour is not plotted and contours with negative values are dashed. (b) Vertical profile of the heating.

forcing as a dipole tropical heating anomaly that resembles the positive (negative) phase of EOF2 (Fig. 1b), with the heating (cooling) center at $0^{\circ}, 90^{\circ} \mathrm{E}$, and cooling (heating) center at $0^{\circ}, 165^{\circ} \mathrm{E}$. It should be noted that the contribution of EOF1 may not be negligible especially when taking into account its tripolar structure.

Three sets of experiments are conducted:

1) control run: climatological forcing,

2) $+\mathrm{MJO}$ run: climatological forcing plus a $+\mathrm{MJO}$ thermal forcing, and

3) $-\mathrm{MJO}$ run: climatological forcing plus a $-\mathrm{MJO}$ thermal forcing.

For each set of experiments, an ensemble of 360 integrations is performed from initial conditions that are taken from the winter observations. These initial conditions are separated by 15 days to make them relatively independent. Each model run lasts 30 days. For the $+\mathrm{MJO}$ and $-\mathrm{MJO}$ runs, the tropical heating anomaly is added to the temperature equation. No forcing anomaly is applied for the vorticity, divergence, or mass equations. To mimic the MJO, the heating anomaly is switched on at $t=0$ and persists for 9 days. After that, the heating anomaly is gradually reduced and it is set to zero after day 11 . We tested different heating periods from 5 to 30 days and found that the results are qualitatively similar.

The heating perturbation represents deep convection in the tropics. The perturbation heating and cooling sources have a semimajor axis of $40^{\circ}$ of longitude and a semiminor axis of $11^{\circ}$ of latitude. The magnitude of the heating is proportional to the squared cosine of the distance from the center. The heating anomaly has a vertical profile of $(1-\sigma) \sin [\pi(1-\sigma)]$, which peaks at $\sigma=0.45$ with a vertically averaged heating rate at the center of $2.5 \mathrm{~K} \mathrm{day}^{-1}$. This rate is equivalent to a latent heating associated with a precipitation of $1 \mathrm{~cm} \mathrm{day}^{-1}$. The vertically averaged heating anomaly for $+\mathrm{MJO}$ forcing is illustrated in Fig. 2. The control and both perturbation runs start from the same 360 initial conditions. The only difference between the $+\mathrm{MJO}$ and $-\mathrm{MJO}$ runs is the sign of dipole heating anomaly. The daily ensemble average for each set of experiments is calculated. The difference between a perturbation run and the control run represents a forced signal by the anomalous forcing field.

\section{Nonlinearity}

In this section, we analyze the nonlinearity of the extratropical response to tropical MJO forcing. The observed MJO-related teleconnections are compared with the numerical experiments. As the extratropical atmospheric response to a tropical heating anomaly has a similar structure at different vertical levels, we focus on the geopotential height response at the 500-hPa level.

\section{a. Observed teleconnections}

We first present the MJO-related teleconnection in the observations. To see the nonlinearity of the MJOrelated teleconnection in the real world, Fig. 3 shows the two-pentad lagged composites of pentad-mean 500-hPa geopotential height anomaly with respect to MJO phases 2 and 6. The observed MJO phases are defined according to the bivariate MJO index of Wheeler and Hendon (2004). As demonstrated in the OLR and precipitation anomalies associated with different MJO phases-for example, Fig. 8 of Wheeler and Hendon (2004) and Fig. 3 of Lin et al. (2009)—MJO phase 2 (6) 
a) PHASE 2 lag2

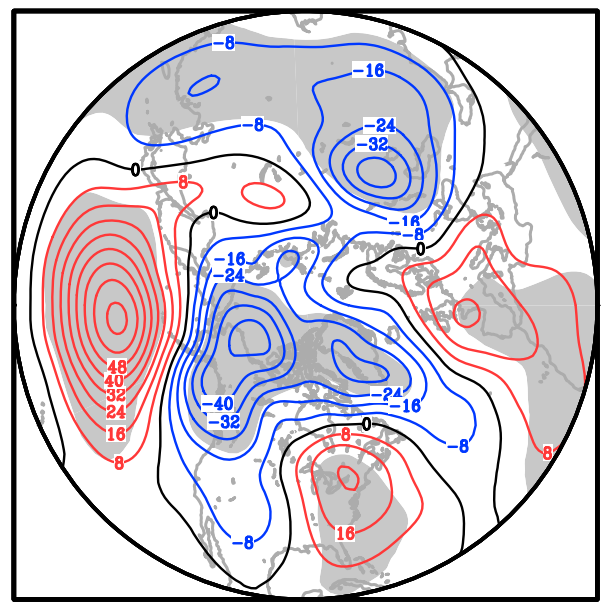

c) Linear Component

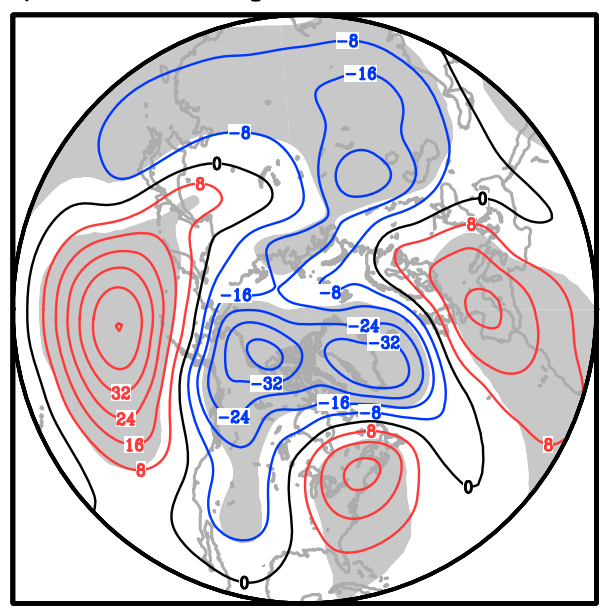

\section{b) PHASE 6 lag2}

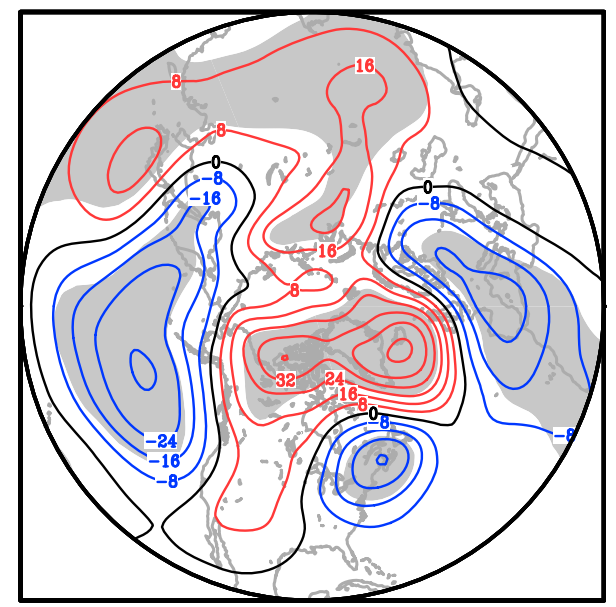

d) Nonlinear Component

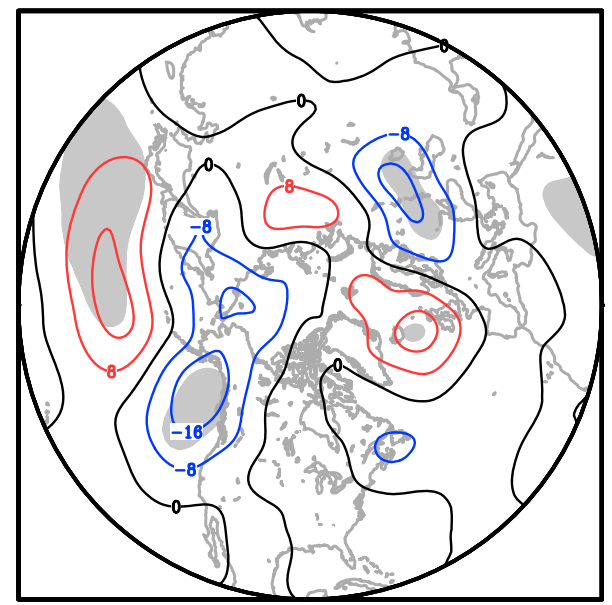

FIG. 3. Two-pentad lagged composites of the pentad-mean 500-hPa geopotential height anomaly of the NCEPNCAR reanalysis with respect to MJO phases (a) 2 and (b) 6. (c) Linear and (d) nonlinear components of the 500 -hPa geopotential height anomaly. The contour interval is $8 \mathrm{~m}$. The shaded areas represent values different from zero with a significance level of 0.05 according to a Student's $t$ test.

corresponds to an equatorial west-east dipole convection anomaly with enhanced (suppressed) convection in the eastern Indian Ocean and reduced (enhanced) convection in the western Pacific and, therefore, with a diabatic heating anomaly similar to the $+\mathrm{MJO}(-\mathrm{MJO})$ experiment. In previous studies (e.g., Lin et al. 2009), composites were made with respect to MJO phases 3 and 7 to study the MJO connection with the NAO. In the present study we study teleconnection development also in the North Pacific. Here for lag $=2$ phases 2 and 6 are used, which are about one pentad earlier than phases 3 and 7. Similar results to Fig. 3 can be obtained with lag $=1$ for phases 3 and 7 (not shown). Comparing Fig. 3a with Fig. 3b, the extratropical teleconnection pattern following MJO phase 6 is in general similar to that following MJO phase 2 except with an opposite sign. In the PNA region, a wave train resembling the negative (positive) phase of the PNA pattern (Wallace and Gutzler 1981) is observed to be associated with MJO phase 2 (6). In the North Atlantic domain, the geopotential height anomaly following MJO phase 2 (6) is very similar to the positive (negative) phase of the North Atlantic Oscillation (e.g., Hurrell et al. 2003), which is consistent with the findings of Lin et al. (2009) and Cassou (2008). Another interesting feature is that near the east coast of Asia, associated with MJO phase 2 (6), appears a significant negative (positive) height anomaly that extends northwestward, covers a large portion of the Eurasian continent, and seems connected to the anomalies in the polar region. This 
process likely contributes to the development of the positive and negative NAO following MJO phases 2 and 6 , respectively. We will come back to this point in section 5 .

The teleconnection patterns of MJO phases 2 and 6 are, however, not exactly mirror images of each other. For example, the negative anomaly center in the North Pacific in Fig. $3 \mathrm{~b}$ is located about $30^{\circ}$ to the east of the North Pacific positive anomaly in Fig. 3a. The composite negative NAO anomaly following MJO phase 6 is stronger than the positive NAO anomaly, which follows MJO phase 2. The geopotential height anomaly as a response to a positive MJO forcing can be decomposed of a linear and nonlinear components:

$$
Z_{+}^{\prime}=Z_{\text {linear }}^{\prime}+Z_{\text {nonlinear }}^{\prime}
$$

where $Z_{+}^{\prime}=Z_{+}-Z_{c}$ is the geopotential height response to a positive forcing (i.e., departure of the geopotential height $Z_{+}$from the climatology $Z_{c}$ ) and $Z_{-}^{\prime}=Z_{-}-Z_{c}$ the response to a negative forcing. The linear and nonlinear components are defined as

$$
Z_{\text {linear }}^{\prime}=\frac{Z_{+}^{\prime}-Z_{-}^{\prime}}{2} \text { and } Z_{\text {nonlinear }}^{\prime}=\frac{Z_{+}^{\prime}+Z_{-}^{\prime}}{2},
$$

respectively.

Such decomposition is similar to that described in previous studies (Hoerling et al. 1997; Lin and Derome 2004; Lin et al. 2007), where the linear component was represented as the response difference between the positive and negative forcing and the nonlinear component was estimated as their summation.

Shown in Figs. 3c and 3d are the linear and nonlinear components of 500-hPa geopotential height anomalies following MJO phases 2 and 6. Our definition makes sure that the sum of Figs. 3c and 3d is Fig. 3a; that is, (1) is satisfied. As can be seen, the linear component dominates, with stronger amplitude and larger area of statistically significant anomaly than the nonlinear component. The nonlinear component is statistically significant in the North Pacific region, reflecting the phase shift of the anomaly center between MJO phases 2 and 6 . The stronger negative NAO of MJO phase 6 than the positive NAO of MJO phase 2 is also reflected in Fig. 3d.

\section{b. Model results}

Here we analyze the development of extratropical response to tropical MJO forcing in the numerical experiments. Comparison is made on the time evolution and the difference in responses between the $+\mathrm{MJO}$ and $-\mathrm{MJO}$ runs.
Shown in Fig. 4 is the $500-\mathrm{hPa}$ geopotential height response for the $+\mathrm{MJO}$ run at 2-day intervals from days 4 to 14 , which is calculated as the difference of 360-member ensemble-mean daily values between the $+\mathrm{MJO}$ run and the control run. A dipole subtropical response pattern, with negative anomalies near the east coast of Asia and positive anomalies in the North Pacific, appears at day 4 . These two anomaly centers are formed respectively as atmospheric response to the dipole equatorial forcing of the $+\mathrm{MJO}$ - that is, heating in the eastern Indian Ocean and cooling in the western Pacific (Fig. 2). They both intensify with time, reaching their maximum amplitude around day 10 , and then decay slowly. From day 8 , a downstream wave train is seen to develop to the east side of the North Pacific positive anomaly, with a negative anomaly center over Alaska. By day 12, a positive anomaly center starts to develop in eastern North America and intensifies afterward. The anomaly centers of the wave train remain stationary, while the wave energy seems to propagate eastward. On the other hand, although the negative anomaly near the east coast of Asia has a stationary center, its area extends northwestward. By day 12, negative geopotential height anomalies are found in the polar region of the North Atlantic. This is also consistent with the observations (Fig. 3a).

The development of the $-\mathrm{MJO}$ response is illustrated in Fig. 5. Up to day 6, the response pattern looks similar to that of the +MJO run, but with the sign reversed. After day 6, the negative center in the North Pacific begins to move eastward while intensifying, reaching its maximum around day 12 . By day 14 , this negative center is located about $30^{\circ}$ to the east of the positive North Pacific response center of the + MJO run. Similar development of the midlatitude wave train as in the $+\mathrm{MJO}$ run is observed, although the centers are stronger and farther to the east than their counterparts in the $+\mathrm{MJO}$ run. The positive anomaly near the east coast of Asia develops faster after day 6 , with a stronger northwestward extension, than the corresponding negative anomaly in the $+\mathrm{MJO}$ run. By day 14, the north part of Europe and the polar region of North Atlantic are covered by positive anomalies.

As is seen from the above analysis, differences between the $+\mathrm{MJO}$ and $-\mathrm{MJO}$ responses start to appear after about 1 week of integration, when the wave train centers over the North Pacific and North American region in the -MJO run start to shift eastward compared to the + MJO run. Therefore, linear response is dominant within 1 week, and nonlinearity becomes important after that. To assess the nonlinearity in the response, the linear and nonlinear parts of the $500-\mathrm{hPa}$ geopotential height anomaly averaged over 5 days from days 11 to 15 
a) +MJO Day4

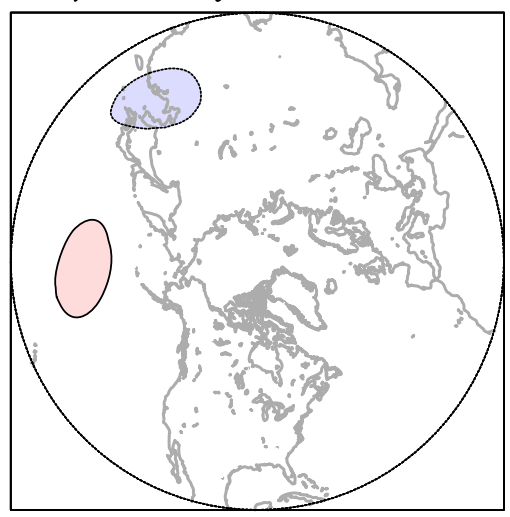

d) +MJO Day10

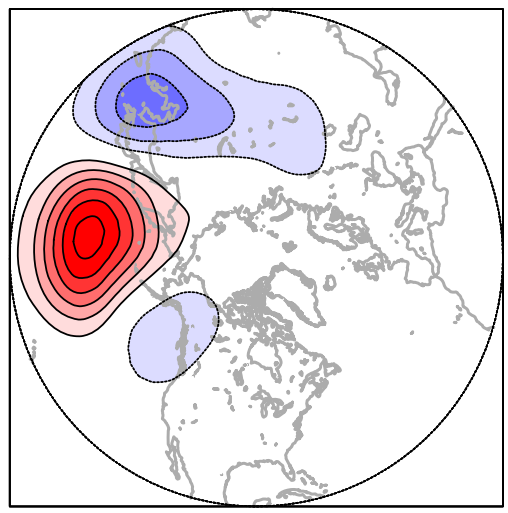

b) +MJO Day6

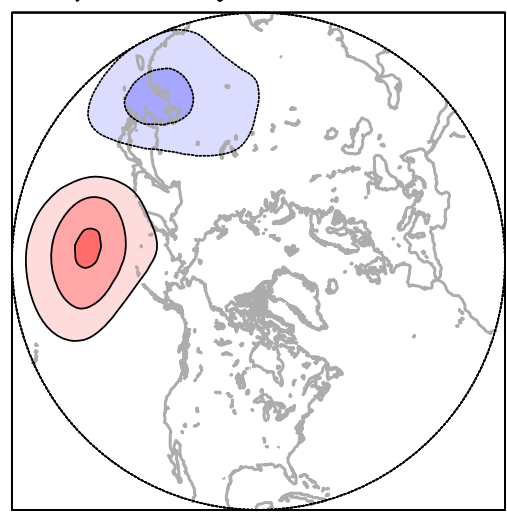

e) +MJO Day12

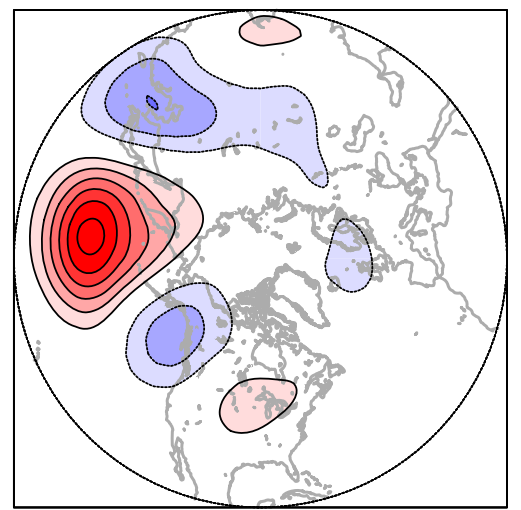

c) +MJO Day8

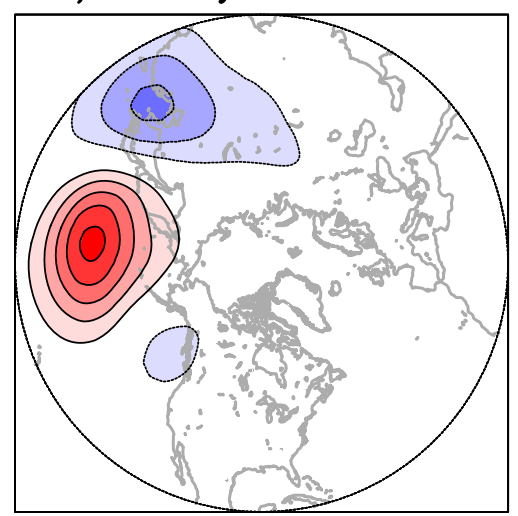

f) +MJO Day14

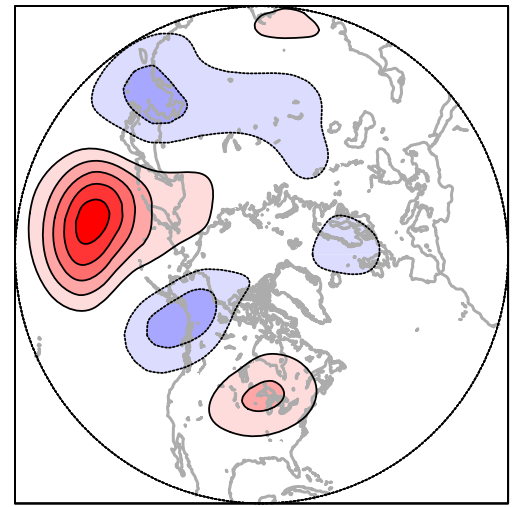

FIG. 4. The 500-hPa geopotential height response to +MJO forcing from days 4 to 14 at a 2 -day interval. The contour interval is $8 \mathrm{~m}$. The zero contour is omitted. Red and blue shaded areas indicate values greater than $8 \mathrm{~m}$ and less than $-8 \mathrm{~m}$, respectively.

are plotted in Fig. 6. Comparing Figs. $6 \mathrm{a}$ and $6 \mathrm{~b}$, it is clear that over the Pacific-North American region the anomaly centers of response in the $-\mathrm{MJO}$ run are stronger than and appear to the east of that in the $+\mathrm{MJO}$ run. The linear response (Fig. 6c) is stronger and more statistically significant than the nonlinear component (Fig. 6d). The linear response component is manifested by a wave train across the North Pacific and North America, as well as a north-south dipole over the North Atlantic and the Eurasian continent. The nonlinear response component is statistically significant in the Pacific-North American region, reflecting the phase shift of wave train between the $+\mathrm{MJO}$ and $-\mathrm{MJO}$ runs. Compared with Fig. 3, the numerical model simulates well the large-scale linear and nonlinear features of the MJO-related teleconnections.

\section{Dependence on the initial condition}

In reality, $\mathrm{MJO}$ events are different from each other, and the atmospheric response to MJO forcing differs from case to case as well. This is because the detailed structure of the MJO heating varies as well as the midlatitude basic state where the MJO-induced Rossby wave propagates. The dependence of the MJO teleconnection on basic state was discussed in previous studies (e.g., Roundy et al. 2010; Henderson et al. 2017).

Here we are interested in how the atmospheric response depends on midlatitude flow assuming there is no change in the tropical MJO heating structure. We approach this problem from a viewpoint of subseasonal prediction. The midlatitude flow that provides a basic state for the MJO-induced teleconnection changes during the forecast period and is unknown at the time of forecast. Instead of studying the relationship between the MJO teleconnection and the basic state, we investigate its dependence on the atmospheric state before the forecast-that is, the initial condition. It is likely that the initial state of the extratropical flow, at least its low-frequency component, is persistent as a basic state during the forecast on a subseasonal time scale. 
a) -MJO Day4

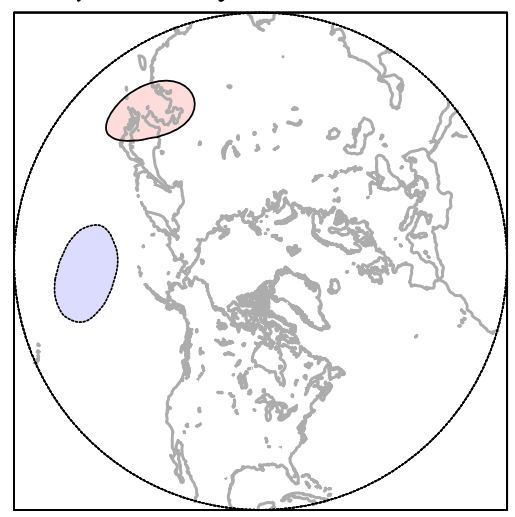

d) -MJO Day10

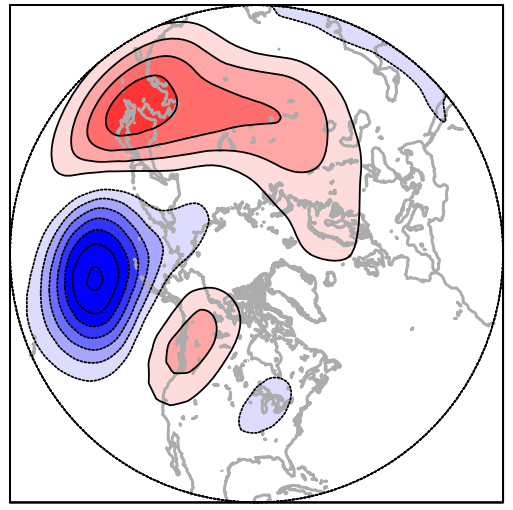

b) - MJO Day6

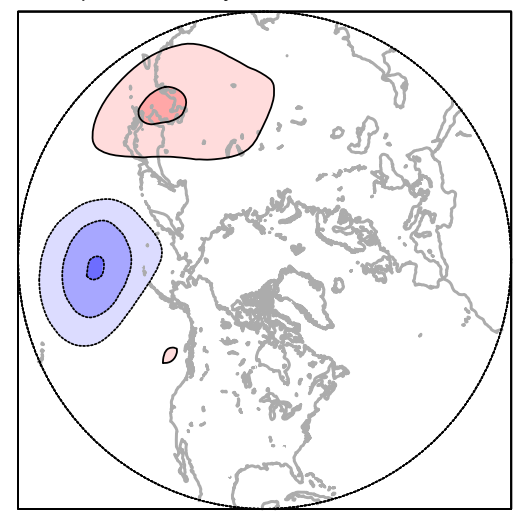

e) -MJO Day12

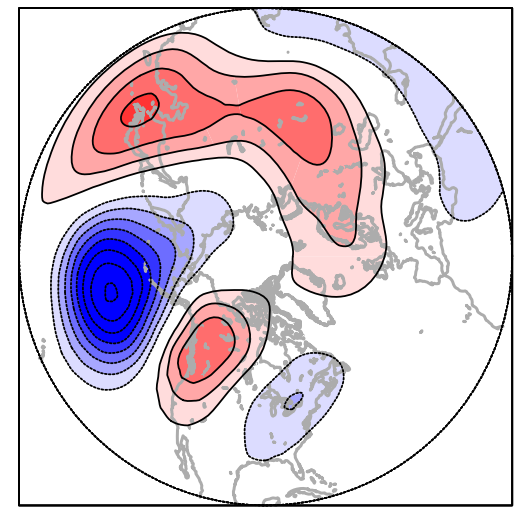

FIG. 5. As in Fig. 4, but for -MJO forcing. c) -MJO Day8

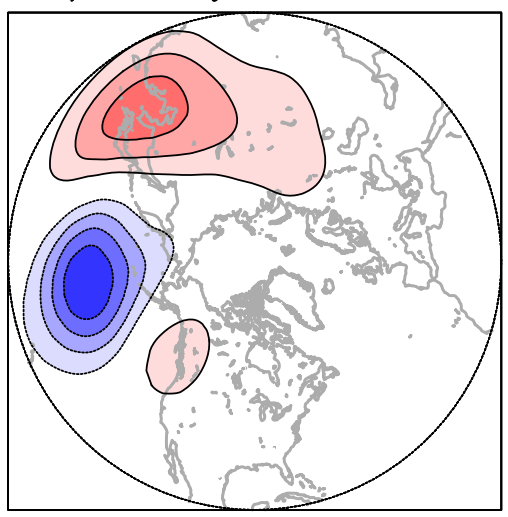

f) -MJO Day14

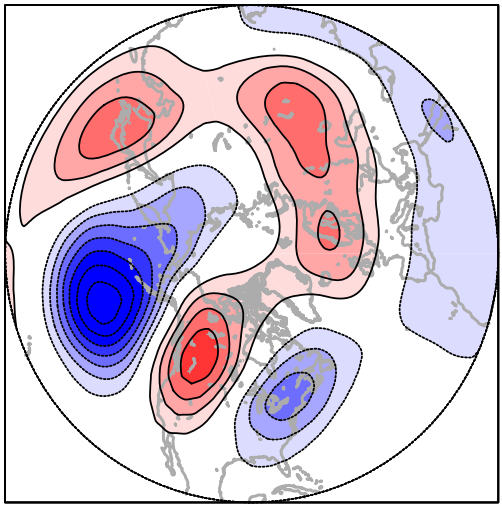

FiG. 5. As in Fig. 4, but for $-\mathrm{MJO}$ forcing.

As described in section 2, a set of 360 integrations were performed with the same tropical positive or negative MJO forcing. Thus, 360 responses can be calculated with respect to the ensemble mean of the control run. The variation of response among the 360 members is caused by differences in initial conditions. Figures $6 \mathrm{a}$ and $6 \mathrm{~b}$ illustrate the ensemble-mean $500-\mathrm{hPa}$ geopotential height response averaged from days 11 to 15 for $+\mathrm{MJO}$ and $-\mathrm{MJO}$ forcing, respectively. The spread of response among the 360 members, which is calculated as the standard deviation of the $500-\mathrm{hPa}$ geopotential height anomaly averaged from days 11 to 15 , is shown in Fig. 7. As can be seen, large member-to-member variability occurs in the midlatitude sector from East Asia across the North Pacific to North America, with a maximum in the eastern North Pacific. The -MJO forcing (Fig. 7b) produces stronger intermember variability in the response than the +MJO forcing (Fig. 7a).

To identify the dominant spatial patterns of the response, an EOF analysis is performed on the 360 individual members of the $500-\mathrm{hPa}$ geopotential height response averaged from days 11 to 15 , forced with + MJO forcing. The two leading modes, EOF1 and EOF2, are plotted in Fig. 8, which account for $23 \%$ and $14 \%$ of the total variance, respectively. The principal component (PC) of each EOF mode represents its amplitude for each member. Compared to the ensemblemean response (Fig. 6a), EOF2 (Fig. 8b) has the same spatial distribution, indicating that this mode represents strengthening or weakening of amplitude of the ensemble-mean response. EOF1 (Fig. 8a), on the other hand, is in quadrature with Fig. 6a. Thus a positive (negative) phase of EOF1 represents an eastward (westward) shift of the response relative to the ensemble-mean response.

The initial state of upper-tropospheric flow for each member is calculated as the 5-day-averaged $200-\mathrm{hPa}$ zonal wind (U200) before the start of integration; that is, from day -5 to day -1 . Shown in Figs. $9 a$ and $9 b$ are linear regressions of the 5-day-averaged initial U200 to the leading days $11-15$ response modes (PC1 and PC2). The shaded area represents the wintertime 
a) + MJO Day11-15

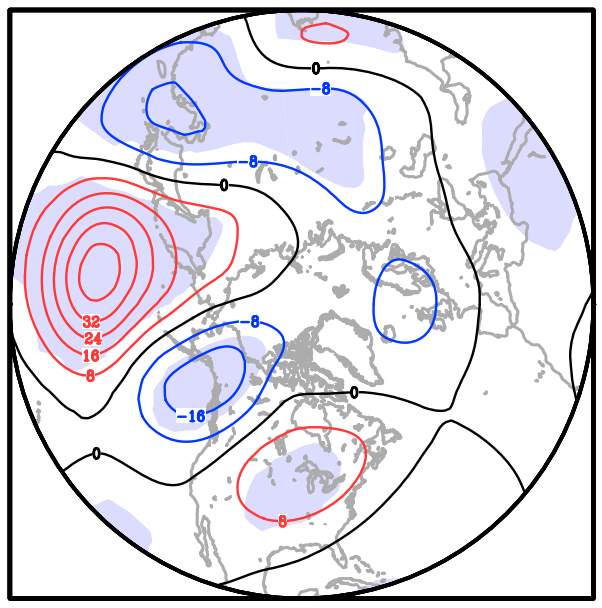

c) Linear Component

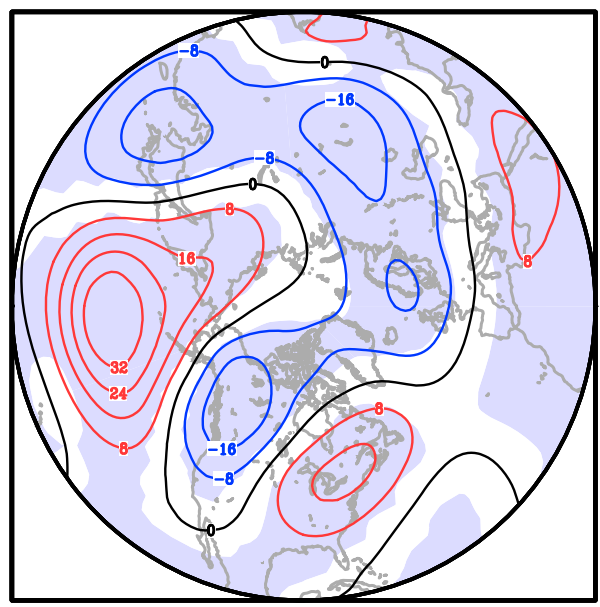

b) -MJO Day11-15

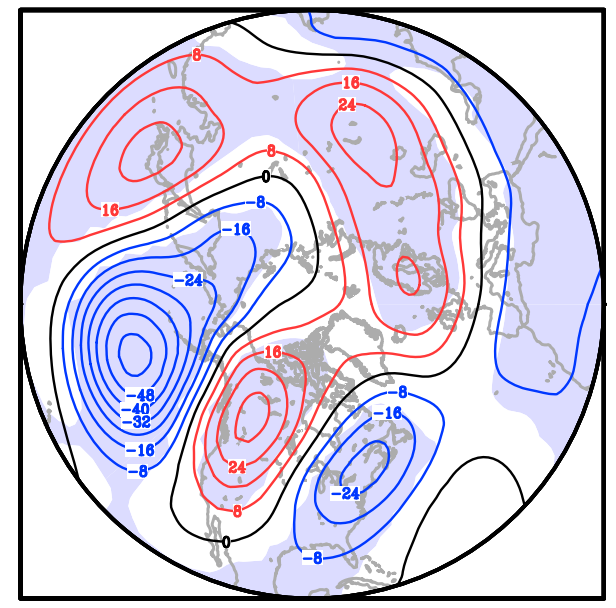

d) Nonlinear Component

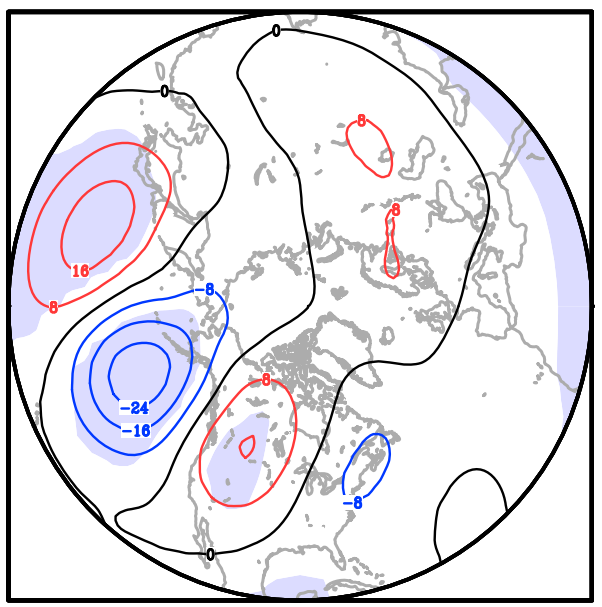

FIG. 6. The 500-hPa geopotential height response averaged between days 11 and 15 for (a) $+\mathrm{MJO}$ and (b) - MJO forcings. (c) Linear and (d) nonlinear component of the 500-hPa geopotential height response. The contour interval is $8 \mathrm{~m}$. The shaded areas represent values different from zero with a significance level of 0.05 according to a Student's $t$ test.

climatological extratropical westerly jets with wind speed exceeding $40 \mathrm{~m} \mathrm{~s}^{-1}$. In Fig. 9a, positive regression coincides with the climatological westerly jet in the subtropical Pacific. This indicates that when there is an intensification of the westerly jet in the subtropical Pacific, the atmospheric response to the +MJO forcing would tend to be a positive phase of EOF1-that is, an eastward shift of the response relative to the ensemblemean response. On the other hand, if the subtropical Pacific westerly jet weakens, a westward shift of the response relative to the ensemble-mean response would likely happen.

From Fig. 9b, on the other hand, positive and negative regressions are seen on the south and north sides of the Pacific climatological extratropical westerly jet, respectively, which indicates a south-north shift of the jet. Therefore, when there is a southward shift of the westerly jet in the subtropical Pacific, the atmospheric response to the $+\mathrm{MJO}$ forcing would tend to be a positive phase of EOF2-that is, an intensification of the response relative to the ensemble-mean response. On the other hand, if the subtropical Pacific westerly jet moves northward, the response would likely weaken.

The above analysis is also performed for the $360-\mathrm{MJO}$ forcing runs. Similar conclusions can be made for the response to the $-\mathrm{MJO}$ forcing as the $+\mathrm{MJO}$ forcing. It should be noted that the model integrations start on day 0 . Days -5 to -1 represents a 5 -day average before the model integration. This is to get the subseasonal signal before the model integration. Hopefully 
a) +MJO Day11-15

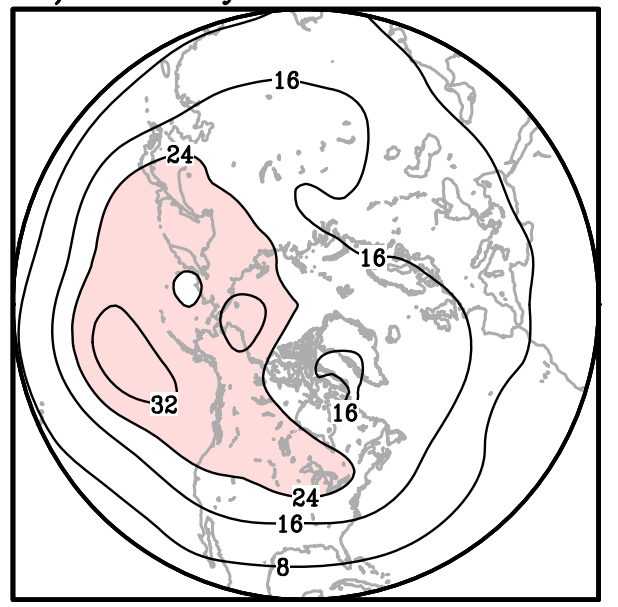

b) -MJO Day11-15

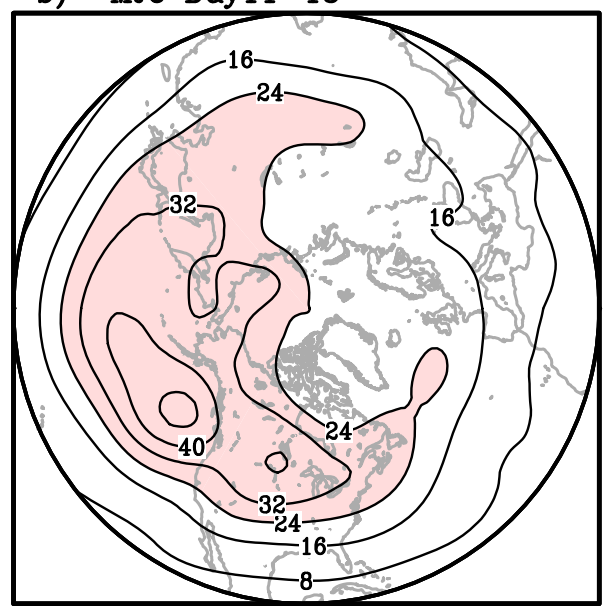

FIG. 7. Spread of 500-hPa geopotential height response averaged between days 11 and 15 among ensemble members for (a) $+\mathrm{MJO}$ and (b) $-\mathrm{MJO}$ forcings. The contour interval is $8 \mathrm{~m}$.

such information is helpful for real-time subseasonal prediction.

\section{Discussion}

The longitudinal phase shift of the extratropical response of $+\mathrm{MJO}$ forcing compared to that of $-\mathrm{MJO}$ forcing as discussed in section 3 is similar to the nonlinearity in the El Niño and La Niña responses, as was found in observational data (Hoerling et al. 1997; Lin and Derome 2004) and numerical study (Lin et al. 2007).
In these studies, the negative geopotential height anomaly in the North Pacific as a response to an El Niño that has a positive diabatic heating anomaly in the central tropical Pacific was observed to be located about $35^{\circ}$ to the east of the positive geopotential height anomaly response of a La Niña. The common feature of a - MJO forcing discussed in the present study and an El Niño is that both have an anomalous heating anomaly, while both + MJO and La Niña have a cooling in the equatorial western-central Pacific. Hoerling et al. (1997) found that the maximum tropical rainfall anomalies are a) EOF $123 \%$

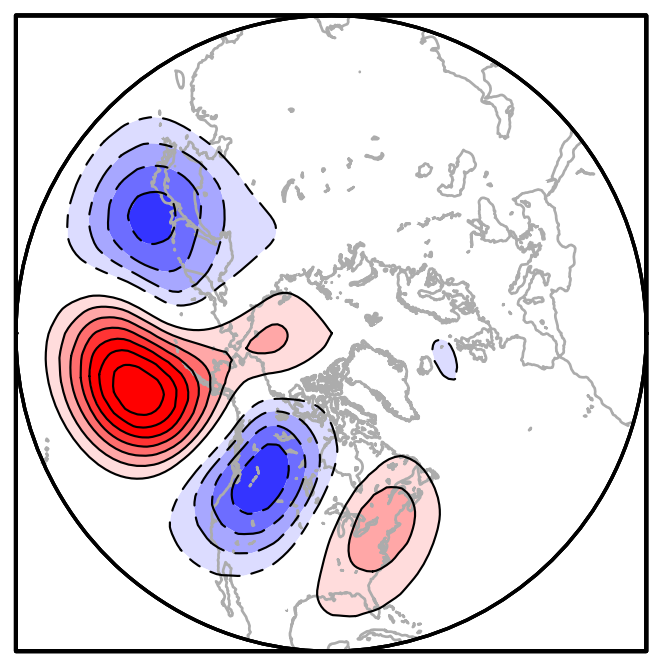

b) EOF $214 \%$

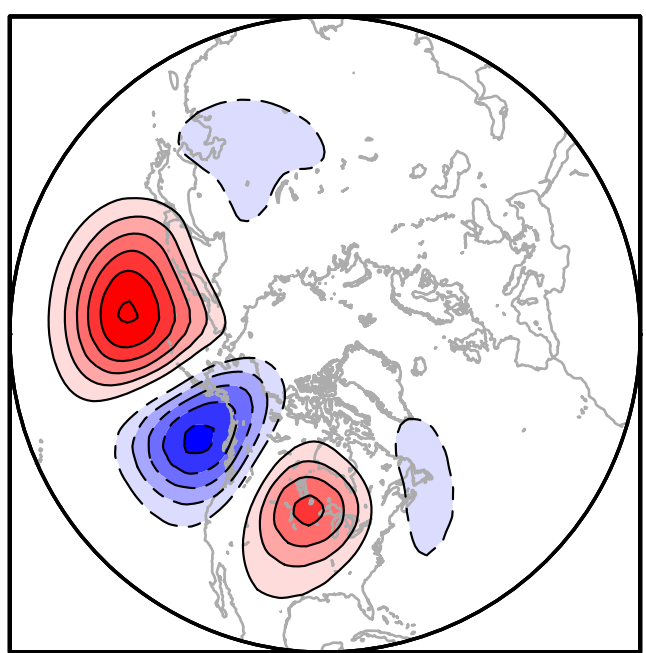

FIG. 8. (a) EOF1 and (b) EOF2 of the 500-hPa geopotential height (Z500) response averaged between days 11 and 15 represented as regressions of 5-day-averaged Z500 anomaly onto the respective PC. The magnitude corresponds to one standard deviation of the PC. The contour interval is $4 \mathrm{~m}$. The zero contour is omitted. Red and blue shaded areas indicate values greater than $4 \mathrm{~m}$ and smaller than $-4 \mathrm{~m}$, respectively. 
a) U200-IC5days reg to PC1

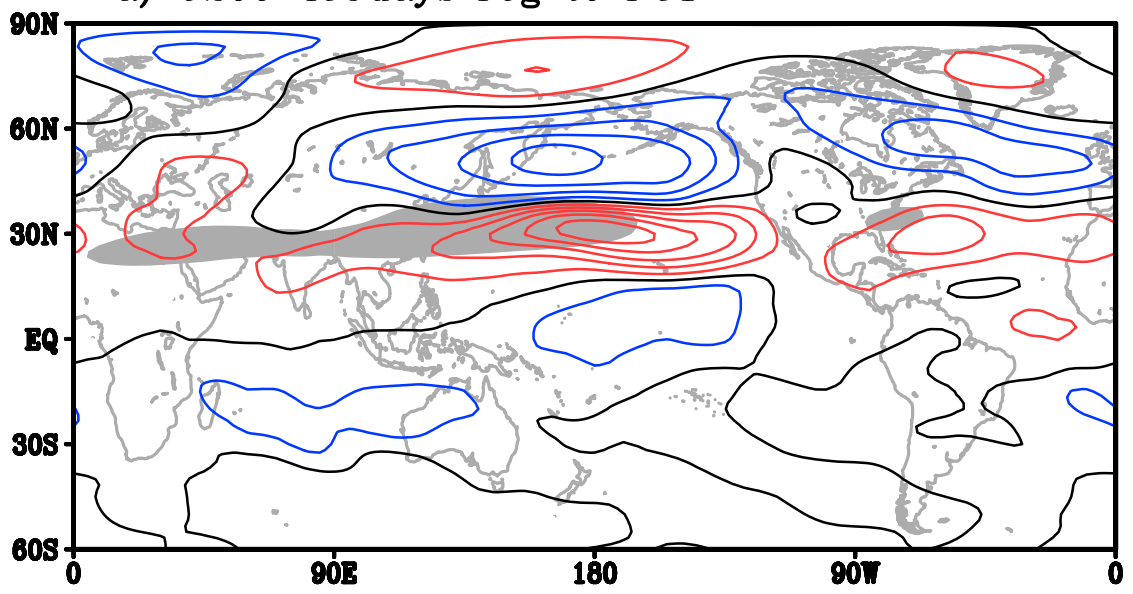

b) U200-IC5days reg to PC2

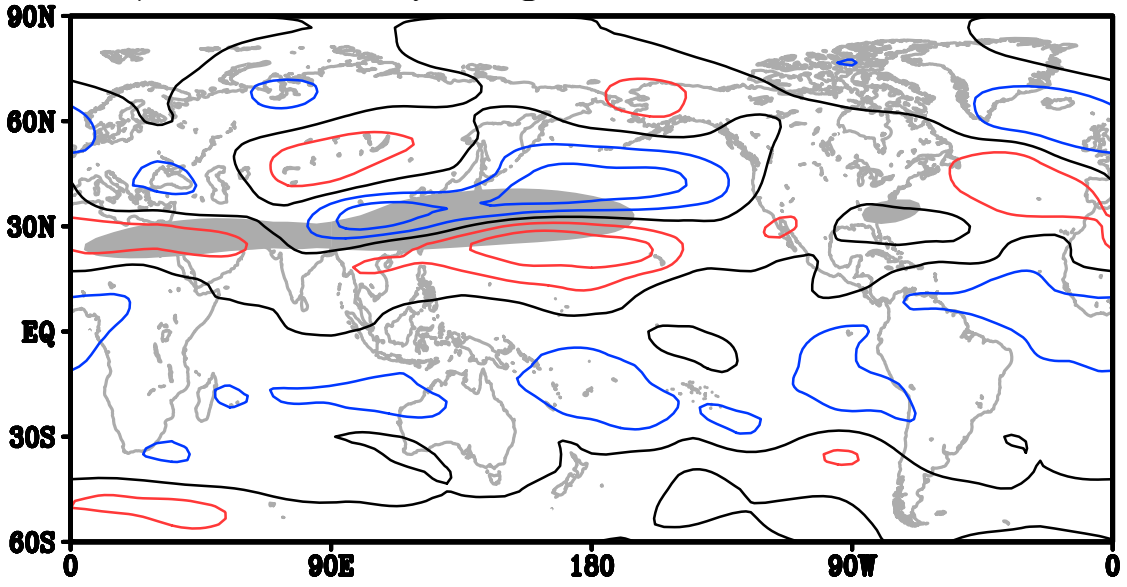

FIG. 9. Linear regression of initial 200-hPa zonal wind with respect to Z500 response PC1 and PC2, respectively. The shaded area represents the climatological westerly jet with wind speed greater than $40 \mathrm{~m} \mathrm{~s}^{-1}$. The contour interval is $1 \mathrm{~m} \mathrm{~s}^{-1}$. Contours in red and blue represent positive and negative values, respectively. Zero contour is in black.

located east of the date line during El Niño events, but west of the date line during La Niña events, and they attribute the nonlinearity of the extratropical response to this phase shift of the tropical deep convection and diabatic heating. Lin and Derome (2004) investigated the dependence of the extratropical atmospheric response on the amplitude of the tropical forcing. By fixing the location of the diabatic forcing anomaly pattern, the effect of the phase shift of the tropical deep convection and diabatic heating was excluded. They still found a nonlinearity in the extratropical response, which they attributed to the nonlinear midlatitude dynamics. In the present study, the $+\mathrm{MJO}$ and $-\mathrm{MJO}$ forcings have the same distribution but opposite signs. It is confirmed that the existence of a response nonlinearity results from atmospheric processes other than a phase shift of the forcing.
To investigate the atmospheric transient response to tropical thermal forcing that resembles El Niño and La Niña, ensemble experiments using the same primitiveequation dry atmospheric model as in the present study were performed by Lin et al. (2007). It was found that the nonlinearity in response is partly associated with tropical wave response. In the tropics, the shape of the Rossby wave response and the zonal extent of the Kelvin wave are not symmetric between El Niño and La Niña, which is associated with the dependence of the wave property on the zonal mean flow. This is especially important in the equatorial region to the west of the forcing, which is likely responsible for the phase shift of the extratropical response in the North Pacific.

There are other possible mechanisms that may lead to the nonlinearity of the extratropical response to tropical 
forcing. Direct response to tropical forcing could change the midlatitude flow, which modifies the wave energy propagation of Rossby waves. Small variations in the basic state could make important differences in the response (Hall and Derome 2000; Ting and Sardeshmukh 1993). Response nonlinearity may also result from interactions with transient eddies. The direct response to tropical forcing could modulate the storm-track activity, which then feeds back onto the direct response (e.g., Lau 1988; Held et al. 1989). Lin et al. (2007) also found that the transient eddy activity in the extratropics feeds back to the response and helps to maintain the nonlinearity.

The stronger and eastward shift of the -MJO response compared to the $+\mathrm{MJO}$ response can be partly explained by the dependence of the response on the basic state. As a response to - MJO forcing, a negative geopotential height anomaly develops in the extratropical North Pacific (Fig. 5), which extends the westerly jet eastward. As discussed in section 4, an extended and strong jet provides a condition to shift the response eastward. Also the enhanced North Pacific low pushes the westerly jet southward, which is favorable for a strong extratropical response.

Previous studies found that in boreal winter about 1015 days after MJO phases 2 and 3 (6 and 7) a positive (negative) phase of the NAO is likely to occur (Lin et al. 2009; Cassou 2008). This is confirmed in Fig. 3 of the present study. The process by which the anomalous NAO is developed following the tropical MJO forcing is not fully understood. As discussed in Lin et al. (2009), one mechanism is the wave activity flux from the North Pacific to the North Atlantic associated with extratropical Rossby waves. However, owing to dissipation the wave amplitude is expected to decrease as the distance with the wave source increases. Therefore the amplification of the NAO, which is far from the wave source in the Pacific, seems difficult to explain by the Rossby wave propagation across the North Pacific.

In addition to the above-discussed Rossby wave propagation, another process is likely important in the NAO development following an MJO forcing. As indicated in Figs. 4 and 5, there is a negative (positive) subtropical geopotential height response near the east coast of East Asia, associated with the equatorial Indian Ocean heating (cooling) of the $+\mathrm{MJO}(-\mathrm{MJO})$ forcing. This geopotential height anomaly extends northwestward, reaching the polar region of the North Atlantic to form the northern center of the NAO pattern at about day 14 (Figs. 4f and 5f). It seems that the northwestward extension of the height anomaly is due to the phase propagation of midlatitude Rossby wave in a weak and northward decreased-zonal-wind basic state. On the other hand, in the tropics to the west side of the tropical
Indian Ocean heating anomaly a pair of tropical Rossby wave gyres straddling the equator are induced (e.g., Matsuno 1966; Gill 1980), which propagate westward. To demonstrate this process, Figs. 10 and 11 present the 200-hPa geopotential height and wind responses to $+\mathrm{MJO}$ and $-\mathrm{MJO}$ forcing, respectively. It is clear in Fig. 11 (-MJO forcing) that near $20^{\circ} \mathrm{N}$ a negative height anomaly extends westward, reaching the subtropical North Atlantic near day 12, which contributes to the southern center of a negative NAO-like pattern in Figs. 5d-f. Although weaker for the $+\mathrm{MJO}$ case, an indication of a positive height anomaly of the Northern Hemisphere branch of the tropical Rossby wave can also be seen in the subtropical North Atlantic (Figs. 10, 4e, and 4f).

\section{Summary and conclusions}

In this study, a primitive-equation atmospheric model is used to study the atmospheric response to tropical MJO forcing. The MJO thermal forcing pattern is defined according to an EOF analysis of tropical pentad-averaged OLR for the 37 extended winters from 1979/80 to 2015/16. The second EOF mode of the OLR is used as the MJO forcing pattern, which is characterized by a dipole structure of convection anomalies, with enhanced convection in the eastern Indian Ocean and reduced convective activity in the western Pacific. With the specified idealized MJO forcing, ensembles of 360 integrations are performed from different initial conditions for a positive and a negative MJO forcing, in addition to a 360-member control run. The daily response is obtained as the difference between the ensemble means of the perturbed run and the control experiment. Two aspects of the extratropical response to the MJO are examined. One is the nonlinearity of the response, which answers the question of whether the response to a positive MJO dipole heating is the mirror image of that to a negative MJO dipole heating. The second aspect is the sensitivity of extratropical response to the initial state, which explores the dependence of the extratropical response on the initial condition of the westerly jet.

Observational analysis with the NCEP-NCAR reanalysis data shows that two-pentad lagged composites of pentad-mean 500-hPa geopotential height anomaly following MJO phases 2 and 6 are asymmetric in the North Pacific-North American region. The negative anomaly center in the North Pacific corresponding to MJO phase 6 is located about $30^{\circ}$ to the east of the North Pacific positive anomaly following MJO phase 2. Also the composite negative NAO following MJO phase 6 is stronger than the positive NAO that follows MJO phase 2 . The numerical experiments are able to largely 
DAY 3
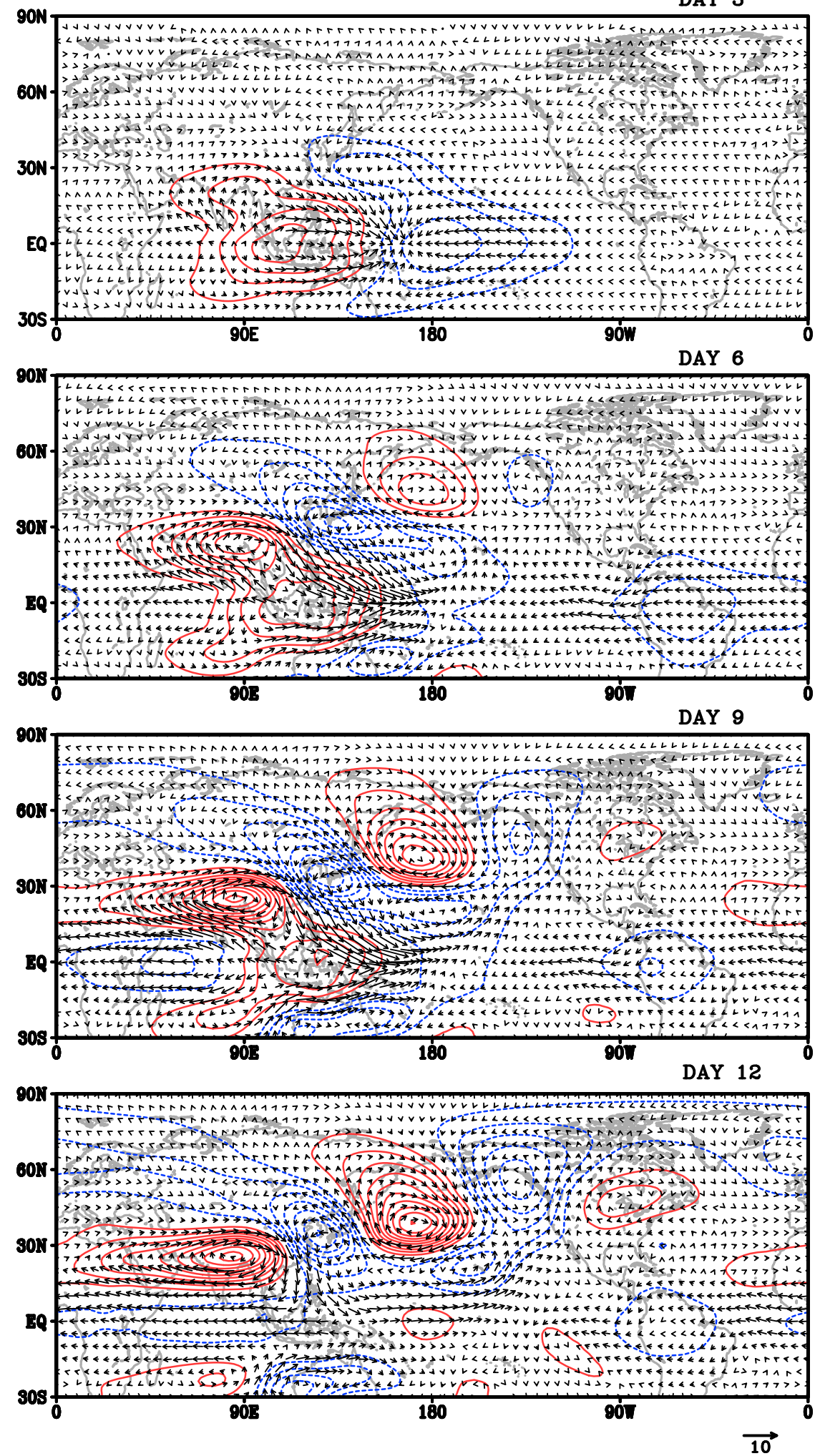

FIG. 10. The 200-hPa geopotential height (contours) and wind (vectors) response to $+\mathrm{MJO}$ forcing from days 3 to 12 at a 3-day interval. The contour interval is $5 \mathrm{~m}$. The zero contour is omitted. Red and blue contours indicate positive and negative values, respectively. The scale vector representing $10 \mathrm{~m} \mathrm{~s}^{-1}$ is shown at the bottom right of the figure. 
DAY 3
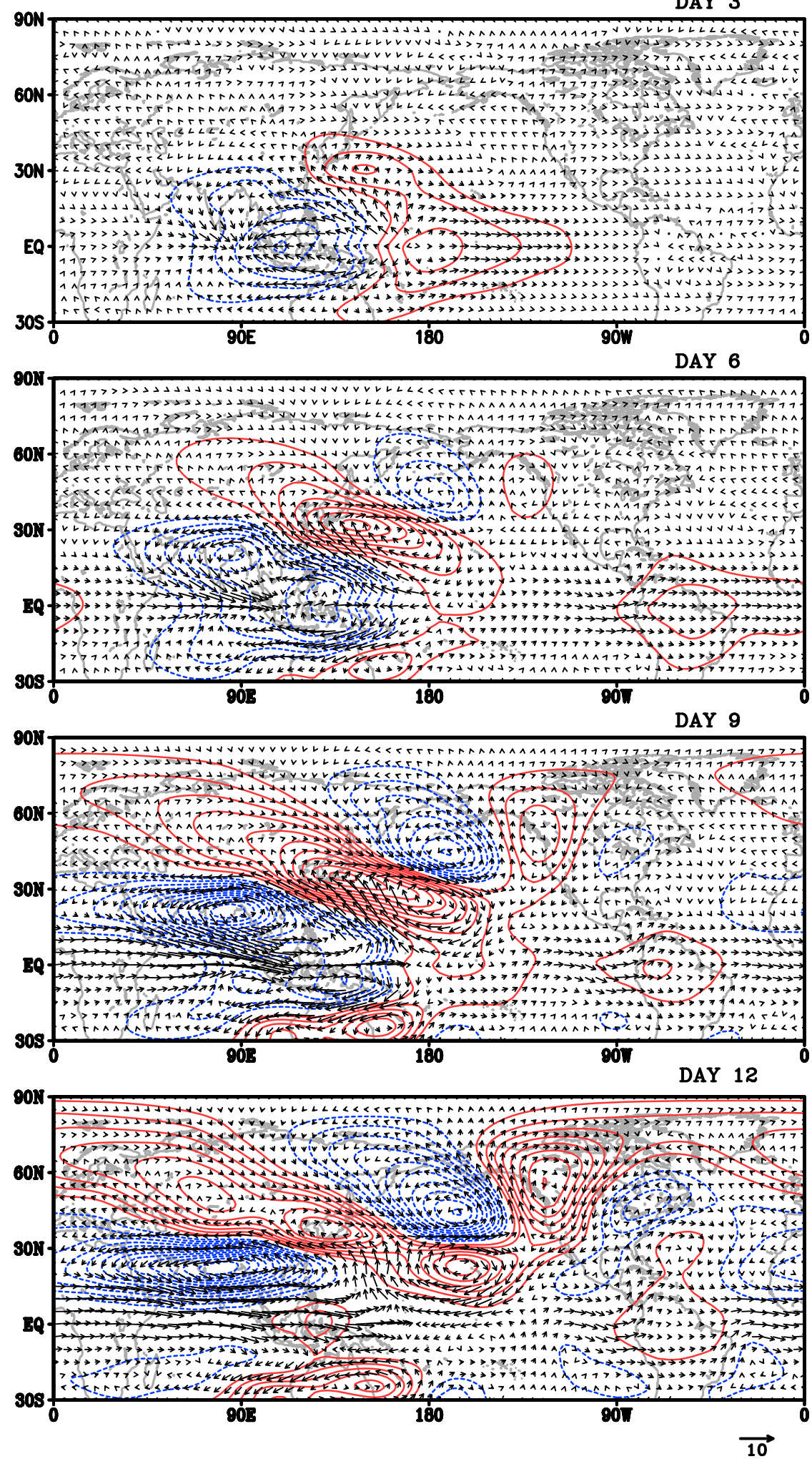

FIG. 11. As in Fig. 10, but for -MJO forcing. 
reproduce the observed nonlinearity in the response. The response in the first week is largely linear. After that, significant asymmetry is found between the response in the positive MJO and the negative MJO.

Large member-to-member variability occurs in the midlatitude sector from East Asia across the North Pacific to North America, with a maximum in the eastern North Pacific. The spread of the response among different members for the $-\mathrm{MJO}$ forcing is bigger than that of the $+\mathrm{MJO}$ forcing. To identify the dominant spatial patterns of the response, an empirical orthogonal function (EOF) analysis is performed on the 360 individual members of the 500-hPa geopotential height response averaged from days 11 to 15 . EOF1 and EOF2 represent an eastward shift and an intensification of the response, respectively. The initial state of the uppertropospheric flow for each member is calculated as the 5-day-averaged 200-hPa zonal wind (U200) before the start of integration. The association of the initial state and the two leading response modes is evaluated. EOF1 is found to be positively correlated with strengthening of the East Asian subtropical upper-troposphere westerly jet, whereas EOF2 is associated with a southward shift of the westerly jet in the initial state.

Acknowledgments. The authors thank Dr. S. Feldstein and two anonymous reviewers, whose comments helped to improve our paper.

\section{REFERENCES}

Baxter, S., S. Weaver, J. Gottschalck, and Y. Xue, 2014: Pentad evolution of wintertime impacts of the Madden-Julian oscillation over the contiguous United States. J. Climate, 27, 7356-7367, https://doi.org/10.1175/JCLI-D-14-00105.1.

Becker, E. J., E. H. Berbery, and R. W. Higgins, 2011: Modulation of cold-season U.S. daily precipitation by the Madden-Julian oscillation. J. Climate, 24, 5157-5166, https://doi.org/10.1175/ 2011JCLI4018.1.

Bladé, I., and D. L. Hartmann, 1995: The linear and nonlinear extratropical response to tropical intraseasonal heating. J. Atmos. Sci., 52, 4448-4471, https://doi.org/10.1175/1520-0469(1995)052<4448: TLANER $>2.0 . \mathrm{CO} ; 2$.

Bond, N. A., and G. A. Vecchi, 2003: The influence of the Madden-Julian oscillation on precipitation in Oregon and Washington. Wea. Forecasting, 18, 600-613, https://doi.org/ 10.1175/1520-0434(2003)018<0600:TIOTMO>2.0.CO;2.

Branstator, G., 1985: Analysis of general circulation model seasurface temperature anomaly simulations using a linear model. Part I: Forced solutions. J. Atmos. Sci., 42, 2225-1241, https://doi.org/10.1175/1520-0469(1985)042<2225: AOGCMS $>2.0 . \mathrm{CO} ; 2$.

Cassou, C., 2008: Intraseasonal interaction between the MaddenJulian oscillation and the North Atlantic Oscillation. Nature, 455, 523-527, https://doi.org/10.1038/nature07286.

Gill, A. E., 1980: Some simple solutions for heat-induced tropical circulations. Quart. J. Roy. Meteor. Soc., 106, 447-462, https:// doi.org/10.1002/qj.49710644905.
Goss, M., and S. B. Feldstein, 2015: The impact of the initial flow on the extratropical response to Madden-Julian oscillation convective heating. Mon. Wea. Rev., 143, 1104-1121, https:// doi.org/10.1175/MWR-D-14-00141.1.

Hall, N. M. J., 2000: A simple GCM based on dry dynamics and constant forcing. J. Atmos. Sci, 57, 1557-1572, https://doi.org/ 10.1175/1520-0469(2000)057<1557:ASGBOD>2.0.CO;2.

- and J. Derome, 2000: Transients, nonlinearity, and eddy feedback in the remote response to El Niño. J. Atmos. Sci., 57, 3992-4007, https://doi.org/10.1175/1520-0469(2001)058<3992: TNAEFI $>2.0 . \mathrm{CO} ; 2$.

- — - and H. Lin, 2001: The extratropical signal generated by a midlatitude SST anomaly. Part I: Sensitivity at equilibrium. J. Climate, 14, 2035-2053, https://doi.org/10.1175/ 1520-0442(2001)014<2035:TESGBA > 2.0.CO;2.

Held, I. M., S. W. Lyons, and S. Nigam, 1989: Transients and the extratropical response to El Niño. J. Atmos. Sci., 46, 163-174, https://doi.org/10.1175/1520-0469(1989)046<0163: TATERT $>2.0 . \mathrm{CO} ; 2$.

Henderson, S. A., E. D. Maloney, and S.-W. Son, 2017: MaddenJulian oscillation Pacific teleconnections: The impact of the basic state and MJO representation in general circulation models. J. Climate, 30, 4567-4587, https://doi.org/10.1175/ JCLI-D-16-0789.1.

Higgins, R. W., J.-K. E. Schemm, W. Shi, and A. Leetmaa, 2000: Extreme precipitation events in the western United States related to tropical forcing. J. Climate, 13, 793-820, https://doi.org/ 10.1175/1520-0442(2000)013<0793:EPEITW>2.0.CO;2.

Hoerling, M., A. Kumar, and M. Zhong, 1997: El Niño, La Niña, and the nonlinearity of their teleconnections. J. Climate, 10, 1769-1786, https://doi.org/10.1175/1520-0442(1997)010<1769: ENOLNA $>2.0 . \mathrm{CO} ; 2$.

Hoskins, B. J., and D. J. Karoly, 1981: The steady linear response of a spherical atmosphere to thermal orographic forcing. J. Atmos. Sci., 38, 1179-1196, https://doi.org/ 10.1175/1520-0469(1981)038<1179:TSLROA > 2.0.CO;2.

— alistic longitudinally varying flow. J. Atmos. Sci., 50, 16611671, https://doi.org/10.1175/1520-0469(1993)050<1661: RWPOAR $>2.0 . \mathrm{CO} ; 2$.

Hurrell, J. W., Y. Kushnir, M. Visbeck, and G. Ottersen, 2003: An overview of the North Atlantic Oscillation. The North Atlantic Oscillation: Climatic Significance and Environmental Impact, Geophys. Monogr., Vol. 134, Amer. Geophys. Union, 1-35.

Jin, F., and B. J. Hoskins, 1995: The direct response to tropical heating in a baroclinic atmosphere. J. Atmos. Sci., 52, 307-319, https:// doi.org/10.1175/1520-0469(1995)052<0307:TDRTTH>2.0.CO;2.

Kalnay, E., and Coauthors, 1996: The NCEP/NCAR 40-Year Reanalysis Project. Bull. Amer. Meteor. Soc., 77, 437-471, https:// doi.org/10.1175/1520-0477(1996)077<0437:TNYRP>2.0.CO;2.

Karoly, D. J., 1983: Rossby wave propagation in a barotropic atmosphere. Dyn. Atmos. Oceans, 7, 111-125, https://doi.org/ 10.1016/0377-0265(83)90013-1.

Lau, N.-C., 1988: Variability of the observed midlatitude storm tracks in relation to low-frequency changes in the circulation pattern. J. Atmos. Sci., 45, 2718-2743, https://doi.org/10.1175/ 1520-0469(1988)045<2718:VOTOMS >2.0.CO;2.

L'Heureux, M. L., and R. W. Higgins, 2008: Boreal winter links between the Madden-Julian oscillation and the Arctic Oscillation. J. Climate, 21,3040-3050, https://doi.org/10.1175/2007JCLI1955.1.

Liebmann, B., and C. A. Smith, 1996: Description of a complete (interpolated) outgoing longwave radiation dataset. Bull. Amer. Meteor. Soc., 77, 1275-1277. 
Lin, H., and J. Derome, 2004: Nonlinearity of extratropical response to tropical forcing. J. Climate, 17, 2597-2608, https://doi.org/ 10.1175/1520-0442(2004)017<2597:NOTERT>2.0.CO;2.

—, and G. Brunet, 2009: The influence of the Madden-Julian oscillation on Canadian wintertime surface air temperature. Mon. Wea. Rev., 137, 2250-2262, https://doi.org/10.1175/ 2009MWR2831.1.

— J. Derome, and G. Brunet, 2007: The nonlinear transient atmospheric response to tropical forcing. J. Climate, 20, 5642 5665, https://doi.org/10.1175/2007JCLI1383.1.

- — - and —, 2009: An observed connection between the North Atlantic Oscillation and the Madden-Julian oscillation. J. Climate, 22, 364-380, https://doi.org/10.1175/ 2008JCLI2515.1.

,$- \ldots$, and R. Mo, 2010: Impact of the Madden-Julian oscillation on wintertime precipitation in Canada. Mon. Wea. Rev., 138, 3822-3839, https://doi.org/10.1175/2010MWR3363.1.

Lukens, K. E., S. B. Feldstein, C. Yoo, and S. Lee, 2017: The dynamics of the extratropical response to Madden-Julian Oscillation convection. Quart. J. Roy. Meteor. Soc., 143, 1095-1106, https://doi.org/10.1002/qj.2993.

Matsuno, T., 1966: Quasi-geostrophic motion in the equatorial area. J. Meteor. Soc. Japan, 44, 25-43, https://doi.org/10.2151/ jmsj1965.44.1_25.

Matthews, A. J., B. J. Hoskins, and M. Masutani, 2004: The global response to tropical heating in the Madden-Julian oscillation during the northern winter. Quart. J. Roy. Meteor. Soc., 130, 1991-2011, https://doi.org/10.1256/qj.02.123.

Mo, K. C., and R. W. Higgins, 1998: Tropical convection and precipitation regimes in the western United States. J. Climate, 11, 2404-2423, https://doi.org/10.1175/1520-0442(1998)011<2404: TCAPRI $>2.0$. CO;2.

Mori, M., and M. Watanabe, 2008: The growth and triggering mechanisms of the PNA: A MJO-PNA coherence. J. Meteor. Soc. Japan, 86, 213-236, https://doi.org/10.2151/jmsj.86.213.

Rodney, M., H. Lin, and J. Derome, 2013: Subseasonal prediction of wintertime North American surface air temperature during strong MJO events. Mon. Wea. Rev., 141, 2897-2909, https:// doi.org/10.1175/MWR-D-12-00221.1.

Roundy, P. E., K. MacRitchie, J. Asuma, and T. Melino, 2010: Modulation of the global atmospheric circulation by combined activity in the Madden-Julian oscillation and the El NiñoSouthern Oscillation during boreal winter. J. Climate, 23, 4045-4059, https://doi.org/10.1175/2010JCLI3446.1.
Seo, K.-H., and S.-W. Son, 2012: The global atmospheric circulation response to tropical diabatic heating associated with the Madden-Julian oscillation during northern winter. J. Atmos. Sci., 69, 79-96, https://doi.org/10.1175/2011JAS3686.1.

—, H.-J. Lee, and D. M. W. Frierson, 2016: Unraveling the teleconnection mechanisms that induce wintertime temperature anomalies over the Northern Hemisphere continents in response to the MJO. J. Atmos. Sci., 73, 3557-3571, https:// doi.org/10.1175/JAS-D-16-0036.1.

Ting, M., and P. D. Sardeshmukh, 1993: Factors determining the extratropical response to equatorial diabatic heating anomalies. J. Atmos. Sci., 50, 907-918, https://doi.org/10.1175/ 1520-0469(1993)050<0907:FDTERT $>2.0$. CO 2 .

Vecchi, G. A., and N. A. Bond, 2004: The Madden-Julian Oscillation (MJO) and the northern high latitude wintertime surface air temperatures. Geophys. Res. Lett., 31, L04104, https:// doi.org/10.1029/2003GL018645.

Waliser, D. E., K.-M. Lau, W. Stern, and C. Jones, 2003: Potential predictability of the Madden-Julian oscillation. Bull. Amer. Meteor. Soc., 84, 33-50, https://doi.org/10.1175/BAMS-84-1-33.

Wallace, J. M., and D. S. Gutzler, 1981: Teleconnections in the geopotential height field during the Northern Hemisphere winter. Mon. Wea. Rev., 109, 784-812, https://doi.org/10.1175/ 1520-0493(1981)109<0784:TITGHF $>2.0 . C O ; 2$.

Wheeler, M., and H. H. Hendon, 2004: An all-season realtime multivariate MJO index: Development of an index for monitoring and prediction. Mon. Wea. Rev., 132, 1917-1932, https://doi.org/10.1175/1520-0493(2004)132<1917: AARMMI $>2.0 . \mathrm{CO} ; 2$.

Yao, W., H. Lin, and J. Derome, 2011: Submonthly forecasting of winter surface air temperature in North America based on organized tropical convection. Atmos.-Ocean, 49, 51-60, https://doi.org/10.1080/07055900.2011.556882.

Yoo, C., S. Lee, and S. B. Feldstein, 2012a: Mechanisms of Arctic surface air temperature change in response to the MaddenJulian oscillation. J. Climate, 25, 5777-5790, https://doi.org/ 10.1175/JCLI-D-11-00566.1.

,-- , and $—, 2012 \mathrm{~b}$ : Arctic response to an MJO-like tropical heating in an idealized GCM. J. Atmos. Sci., 69, 2379-2393, https://doi.org/10.1175/JAS-D-11-0261.1.

Zhou, S., M. L'Heureux, S. Weaver, and A. Kumar, 2012: A composite study of the MJO influence on the surface air temperature and precipitation over the continental United States. Climate Dyn., 38, 1459-1471, https://doi.org/10.1007/s00382-011-1001-9. 